\title{
Onde estão meus olhos de robô? $O$ olhar sobre consumismo em Pitty e Caio Fernando Abreu
}

\author{
Simone Damasceno Guardalupe \\ Luciana Zardo Padovani \\ Ana Luisa Feijó Cosme
}

\begin{abstract}
Resumo
As relações de poder e consumo são representadas de maneira simbólica, tanto no conto "Ascensão e queda de Robhéa, manequim e robô", do escritor sul-rio-grandense Caio Fernando Abreu, quanto na letra da música "Admirável chip novo", da cantora baiana Pitty. Há, nas duas obras, uma alusão a uma sociedade robotizada e manipulada seja pelo "poder", seja pelo "sistema". Desse modo, o presente trabalho enfoca a Teoria do Imaginário visando estabelecer relações entre as simbologias presentes nesses dois textos.
\end{abstract}

Palavras-chave: Olhar, Consumo, Imaginário

\begin{abstract}
Power relations and consumption are represented symbolically in both the short story "Ascensão e queda de Robhéa, manequim e robô" , fromthe writer Caio Fernando Abreu, as in the lyrics of the song "Admirável chip novo", by the Bahian singer Pitty . There are in the two works, an allusion to a robot society and manipulated by "power" or by the "system". Thus, the present work focuses on the Theory of the Imaginary in order to establish relationships between the present symbols in these two texts.
\end{abstract}

Keywords: Look ,Consumption, Imaginary

\section{Introdução}

Durante as décadas de 1960 e 1970, a sociedade brasileira passou por transformações no âmbito social, cultural, econômico e político, como a expansão dos grandes centros urbanos, a desnacionalização da economia e o Regime Militar. Além disso, o capitalismo ganhou maior destaque na economia mundial, modelos como o Fordismo ${ }^{1}$ influenciam nas novas relações de trabalho, consumo e produção. Desse modo, o modelo de produção e consumo em massa também se traduzia de forma mais

\footnotetext{
${ }^{1}$ Neste período, o Fordismo ganha maior destaque, como observa Harvey (1994:121): "O que havia de especial em Ford [...] era a sua visão, seu reconhecimento explícito de que a produção de massa significava consumo em massa, um novo sistema de reprodução de força de trabalho, uma nova política de controle e gerência do trabalho, uma nova estética e uma nova psicologia, em suma um novo tipo de sociedade democrática, racionalizada e populista".
}

Revista Leitura v.2 no 54 - Júlio/Dez 2014 - Número temático: Leituras interartes. Onde estão meus olhos de robô? O olhar sobre consumismo em Pitty e Caio Fernando Abreu. Simone D. Guardalupe, Luciana Z. Padovani e Ana L. F. Cosme. p.-179 - 192. 
intensa na efemeridade, tanto dos produtos expostos nas vitrines quanto das relações humanas.

Essas transformações da sociedade influenciaram de modo significativo a produção literária, em especial brasileira, da segunda metade do século XX. Entre autores que se destacaram nesse período, pode-se citar o sul-rio-grandense Caio Fernando Abreu.

Em relação aos sistemas econômicos e seu impacto na sociedade, a literatura de Caio Fernando Abreu recria tais sistemas a partir das múltiplas vivências de seu tempo. No conto "Ascenção e queda de Robhéa, manequim \& robô", percebemos que o escritor procura explorar a efemeridade das relações, através do valor imediatista atribuído às pessoas e aos objetos.

Flávio Loureiro Chaves (1976) apresenta uma síntese sobre o estilo literário de Caio Fernando Abreu, ao definir que o escritor preocupa-se em fazer o depoimento de sua geração, marcando-o com a urgência das coisas que não esperam para serem ditas artificiosamente, traduzindo esse depoimento na violência das situações e na atmosfera opressiva que envolve as suas personagens. Essa violência das situações possui origem na rotina, na banalidade e na implacável organização de um mundo mecanizado. Tais características apontadas por Chaves são identificadas no conto “Ascensão e Queda de Robhéa, Manequim \& Robô" (1975).

Essas mesmas características podem, também, serem relacionadas à música da cantora Pitty "3،Admirável chip novo"(2003).A referida música foi lançada no álbum homônimo, produzido por Rafael Ramos, em abril de 2003. O título faz referência ao livro Admirável mundo novo (1932), de Aldous Huxley, possibilitando o estabelecimento da relação intertextual, já que o livro problematiza comportamentos impostos a uma população, permeados de regras e limites que ditam sua conduta e a impedem de refletir sobre sua condição. Com esse disco, a cantora atingiu o topo da lista dos mais vendidos, com mais de 370 mil cópias. Em comemoração aos dez anos de seu lançamento, a gravadora Polysom produziu o álbum em disco de vinil em 2013, comprovando que nos dias atuais a temática ainda se faz presente no imaginário social.

Considera-se que a música em questão faz uma crítica ao capitalismo,cujas

\footnotetext{
${ }^{2} \mathrm{O}$ conto foi originalmente publicado no livro $O$ ovo apunhalado, em 1975.

${ }^{3}$ Pitty é o nome artístico da cantora de rock baiana Priscila Novaes Leone, nascida em Salvador, em 07 de outubro de 1977. Pitty obteve destaque no meio musical no início dos anos 2000.
} 
relações de poder condicionam as pessoas a realizar determinadas ações. Assim, a população acaba por perder sua individualidade e é manipulada pelo apelo ao consumo.

O período de produção da canção está inserido em um contexto histórico brasileiro teoricamente adverso ao do período ditatorial, enfatizado na obra de Caio Fernando Abreu, sobretudo em razão da eleição de um presidente proveniente do Partido dos Trabalhadores, com bases políticas de esquerda, no ano de 2002, até então inédito no país. Tal configuração contribuiu para uma perspectiva de uma nova administração de caráter mais social, mas também, na vigência do novo governo, houve intensa abertura e estabilidade econômica, trazendo índices positivos de investimentos e elevando o seu conceito perante as grandes potências mundiais, tornando inevitáveis as práticas globalizantes.

Nesse contexto, é possível estabelecer uma relação entre a música da cantora Pitty e o conto de Caio Fernando Abreu, justamente pelo tom crítico dirigido à tentativa de homogeneização cultural, consequência direta das relações capitalistas, as quais delimitam a individualidade dos sujeitos, através do apelo ao consumo e do desenvolvimento tecnológico. Portanto, mesmo em épocas distintas, os dois artistas desenvolvem materialidades próximas em questões temáticas, instigando a pesquisa a respeito de como são construídos, nos dois textos, os elementos que levam a interpretações contestadoras.

Tanto o conto de Caio Fernando Abreu, quanto a música da cantora Pitty trazem a alusão a uma sociedade imaginária em que os indivíduos são manipulados por um "poder" simbólico que pode ser relacionado tanto ao Poder, constituído pelo governo e pela mídia, no conto "Ascensão e queda de Robhéa, manequim \& robô", quanto pelo "sistema", constituído por todos os veículos de divulgação de ideias de consumo e de cerceamento do pensamento. Desse modo, enfoca-se a Teoria do Imaginário, de Gilbert Durand, para a análise comparativa entre o conto do escritor sul-rio-grandense e a letra da música "Admirável chip novo". Procurar-se-áestabelecer de que forma questões como o consumismo, a simbologia do olhar e seu sentido de revelação, a violência simbólica, que desconstrói a subjetividade, e a ideologia de dominação, a qual interpela os sujeitos e do apelo tecnológico que "desumaniza" os indivíduos, estão representadas em ambas as obras.

Como principal contribuição teórica para este trabalho, temos os estudos sobre Imaginário realizados pelo pesquisador francês Gilbert Durand. A teoria do Imaginário Onde estão meus olhos de robô? O olhar sobre consumismo em Pitty e Caio Fernando Abreu. Simone D. Guardalupe, Luciana Z. Padovani e Ana L. F. Cosme. p.-179 - 192. 
se constitui de um trajeto antropológico, que considera os símbolos como um produto das interações sociais, culturais, biológicas e psicológicas do homem: "o Imaginário ou seja, o conjunto das imagens e relações de imagens que constitui o capital pensado do homo sapiens - aparece-nos denominador fundamental onde se vêm encontrar todas as criações do pensamento humano" (DURAND, 2012:18).

No conto e na letra da música analisados observa-se a criação de um mundo simbólico que faz alusão à sociedade e ao homem contemporâneo. Em "Ascensão e queda de Robhéa, manequim \& robô", temos a expressão de uma crítica à sociedade moderna e capitalista, à robotização humana e à solidão causada pela falta de compreensão e pelo egoísmo. Essas mesmas críticas também são expressas na letra da música "Admirável chip novo".

\section{Pane no sistema... Um olhar revelador sobre o consumo}

O conto “Ascensão e Queda de Robhéa, Manequim \& Robô", publicado no livro O ovo apunhalado, traz um universo que faz alusão ao que estava acontecendo com a sociedade brasileira na década de 1970: a repressão do Regime Militar e as transformações sociais e econômicas causadas pela disseminação do Capitalismo pósguerra ${ }^{4}$.

A epidemia que assola a sociedade do conto faz com que os indivíduos se comportem de maneira "anormal" e o Poder tenta moldar os indivíduos que transgridem o sistema, valendo-se da violência:

Não foi fácil contê-los. No sétimo dia morriam pelas esquinas em estilhaços
metálicos e ruídos de ferragens. A epidemia se alastrara de tal modo que se
tornara excessivamente fácil surpreendê-los. Os policiais nem mais se
preocupavam em armar ciladas, disfarçando-se de civis para acompanhar e
prevenir a evolução da peste. Os doentes - assim haviam sido chamados pelo
Poder - não suportavam o processo por mais de sete dias. (ABREU, 1992:31)

Pode-se perceber que em ambas as obras há a presença da violência, tanto no

\footnotetext{
${ }^{4}$ Segundo Zilberman (1991:93) a tomada do poder pelo Exército brasileiro foi apoiada por vários setores civis que, interessados no alinhamento do país com o capitalismo industrial, não aceitavam os rumos populistas e posicionamentos antiimperialistas adotadas pelo governo desde a eleição de João Goulart. Tais características do cenário político influenciaram na produção cultural, inclusive na literatura.
}

Revista Leitura v.2 no 54 - Júlio/Dez 2014 - Número temático: Leituras interartes. Onde estão meus olhos de robô? O olhar sobre consumismo em Pitty e Caio Fernando Abreu. Simone D. Guardalupe, Luciana Z. Padovani e Ana L. F. Cosme. p.-179 - 192. 
sentido literal quanto no sentido simbólico, proporcionada pelas relações de poder e pressão social que envolvem as personagens. No conto de Caio F. vê-se, primeiramente, a violência literal sofrida pelos robôs, que precisam esconder-se da sociedade para tentar sobreviver, já que o Poder objetiva liquidá-los:

Enquanto isso, nos porões de um beco escuro reproduziam-se como ratos remanescentes da epidemia. Quatro deles haviam-se isolado de rumores e máquinas, levando consigo uma grande quantidade de latas de óleo e estimulantes para a sua manutenção e, como não fossem descobertos, organizaram aos poucos um outro sistema de vida. (ABREU, 1992:35)

Ao tomarem conhecimento de que esses indivíduos robotizados estavam se organizando e que pretendiam tomar o Poder, o sistema sente-se ameaçado e novamente usa da violência para com eles:

\begin{abstract}
A rua suspeita foi cercada, os policiais derrubaram as portas com metralhadoras e encurralaram os criminosos contra uma parede úmida onde, com grandes jatos d'água, conseguiram enferrujar lentamente suas articulações. Morreram todos, da mesma maneira que seus precursores (ABREU, 1992:33)
\end{abstract}

Da mesma forma, a personagem Robhéa também passa por essa violência literal e acaba sendo levada para a prisão, para, em seguida, ser encaminhada para um especialista em computadores, servindo como um objeto que está à disposição do Poder. Além dessa forma de violência, a protagonista do conto também passa pela violência simbólica, uma vez que o sistema tenta inseri-la no ciclo consumista da sociedade. Ela é manipulada e passa a ser um ícone da moda, uma das principais ditadoras da maneira de agir da população.

Na música "Admirável chip novo", essas duas formas de violência também são visíveis, pois o eu-lírico é assolado por uma violência simbólica cometida pelo sistema, que o faz consumir cada vez mais. Tal violência toma conta da vida dos indivíduos, que se tornam tão alienados a ponto de não conseguirem distinguir o real do não-real, ou seja, o que é "orgânico" do que é programado. O sistema instalado nos indivíduos ordena que eles consumam cada vez mais: "Pense, fale, compre, beba / Leia, vote, não se esqueça / Use, seja, ouça, diga / Tenha, more, gaste, viva / Pense, fale, compre, beba / Leia, vote, não se esqueça / Use, seja, ouça, diga" (SOUZA, 2003: v. 11-17). 
A violência física está presente na reinstalação do sistema. Na letra da música, o eu lírico relata que alguém está indo até ele para reinstalar o sistema, o que significa que esse momento de lucidez está para acabar, já que sendo reprogramado, ele voltará a agir como um robô. Não é dito quem faz essa reinstalação, o eu lírico se refere a "eles", não apresentando o referente que comete a ação. Sendo assim, pode-se concluir que são os aparelhos ideológicos que fazem essa reprogramação e levam os indivíduos a integrarem novamente o sistema do capitalismo, portanto, a violência simbólica se dá no fato de o eu lírico ser manipulado e perder sua "voz" no momento da reprogramação.

No conto, o primeiro sintoma da "doença" é a mutação que transforma os humanos em máquinas, com o estilhaçamento dos olhos, o enfraquecimento do cérebro e, por último, o enfraquecimento dos membros, levando os indivíduos infectados a caírem pelas ruas. A única solução para os mutantes seria afastarem-se da cidade, pois o Poder ordena o fechamento das oficinas mecânicas e a retirada de estimulantes das farmácias, a fim de evitar que os mutantes sobrevivam por muito tempo:

\footnotetext{
O Poder retirou das farmácias todo o estoque de estimulantes, e ordenou o fechamento de todas as oficinas. Legiões fugiam em direção ao campo, corriam boatos que a proximidade com as máquinas urbanas era o que provocava as mutações. Mas sabendo da possibilidade de se formarem grandes comunidades entre as cidades, o Poder fechou todas as saídas. (ABREU, 1992:32)
}

Ao proibir a sobrevivência dos "doentes", o Poder garante, assim, a manutenção do comportamento da sociedade. Os efeitos da falta de cuidados culminam na queda dos doentes. Essa queda corresponde à queda dos valores e dos interesses individuais da sociedade diante de uma nova organização social, de uma nova forma de agir e de pensar autoritária.

Um dos principais sintomas da queda dos infectados é o estilhaço dos olhos, que são o símbolo da percepção intelectual. Podemos afirmar que o Poder, ao negar a assistência aos "doentes", está querendo exterminar os indivíduos que pensam, que percebem a realidade e que se rebelam contra o sistema. Da mesma forma, na música da cantora Pitty, o eu lírico é calado pelo sistema, que não permite que o mesmo se rebele, já que ele é reprogramado

O olhar está associado à busca pela transcendência. Segundo Durand (2002:151) o olhar seria o "símbolo do julgamento real, da censura do superego, enquanto que o 
olho não passaria de um símbolo enfraquecido, de uma vulgar vigilância (...) seja como for, olho e olhar estão sempre ligados à transcendência". Tal conceito pode ser observado nas ações de Robhéa, no conto, e nas atitudes do robô da letra da música, porque é através da observação do mundo e de suas próprias atitudes que os personagens começam a questionar-se e a questionar a sociedade em que estão inseridos e, com isso,começam uma busca pela transcendência da realidade os cercam.

A personagem Robhéa, que surge na terceira parte do conto de Caio Fernando Abreu, reafirma o conceito de que os "doentes" percebiam o sistema de controle e consumismo mantido pelo poder, pois mesmo salvando-se do extermínio dos "doentes" e obtendo uma carreira de sucesso, a robô rebela-se contra o sistema ao se isolar da sociedade em uma ilha inacessível:

\begin{abstract}
A jovem, conhecida artisticamente como Robhéa, alcançou um sucesso espantoso, galgou todos os degraus da fama em pouquíssimo tempo, acabando por filmar com os cineastas mais em voga no momento, ganhando prêmios e mais prêmios em festivais internacionais e sendo eleita a rainha das atrizes durante cinco carnavais seguidos. Foi no último carnaval que, sem dar explicações, ela fugiu abruptamente do baile, espatifando a fantasia e dizendo em inglês que queria ficar sozinha. Retirou-se para uma ilha deserta e inacessível, onde viveu até o fim de seus dias. (ABREU, 1992:35-36)
\end{abstract}

O simbolismo do olhar está presente na história de Robhéa, pois é ao olhar o ambiente no qual estava inserida, que a personagem foge para uma ilha isolada. A simbologia do olhar ainda pode ser estendida às opiniões que a sociedade emite sobre a protagonista da história, revelando uma incompreensão das atitudes de Robhéa ao abandonar a riqueza, a fama e o prestígio que sua profissão lhe trazia.

O simbolismo do olho e do olhar, relacionados à percepção intelectual, à vigilância e ao julgamento, também estão presentes na letra da música "Admirável chip novo", pois a robô fala que ainda não sabia e não tinha percebido que tudo em sua vida era "programado", ou seja, que tudo que ela sentia ou fazia era fruto de uma manipulação, ou programação do sistema, como observamos nos primeiros versos da canção: “Aonde estão meus olhos de robô?/ Eu não sabia, eu não tinha percebido/ Eu sempre achei que era vivo" (SOUZA, 2003:v. 2-4). É a partir dessa percepção que oeulírico da canção começa a refletir sobre sua condição, como ocorre com a personagem Robhéa do conto do escritor sul-rio-grandense. 
Segundo Chevalier e Gheerbrant (1991:622.) "o olhar aparece como símbolo e instrumento de uma revelação. Mais ainda é um reator e um revelador recíproco de quem olha e de quem é olhado". Em uma perspectiva simbólica, tem-se o símbolo da revelação, tanto de quem olha quanto de quem é olhado nos dois textos, pois há uma revelação tanto dos estados interiores da personagem Robhéa quanto do robô em “Admirável chip novo". Nesse sentido, observamos, também, que em ambos os textos analisados, além de uma revelação dos estados interiores de Robhéa e do eu lírico, há um desvelamento da percepção sobre as realidades nas quais estão inseridas.

A simbologia do olho e do olhar nessas duas obras estão associadas à ideia de revelação e de percepção, porém, tais símbolos se apresentam de maneira diferente no conto e na letra da música. Enquanto que em "Ascenção e queda de Robhéa, manequim \& robô" o estilhaçamento dos olhos é um dos sintomas da quedados indivíduos que se desviam do padrão imposto pelo Poder, na canção, os olhos de robô quando perdidos fazem com que o eulírico "enxergue" com outros olhos sua situação. O estilhaço dos olhos dos "doentes" do texto de Caio Fernando Abreu seria um sintoma do fim de uma ameaça à segurança do Poder da sociedade recriada no conto, do padecimento dos indivíduos que agem de maneira fora do normal e que poderiam questionar o Poder dessa sociedade. Já na letra da música "Admirável chip novo", a desconfiguração do sistema e a perda dos olhos de robô, que fazem com que o eulírico se comporte conforme os padrões programados pelo sistema, resulta na revelação de toda a condição de manipulação a que sua vida estava atrelada.

Robhéa é a única sobrevivente da epidemia, tornando-se modelo de sucesso devido à ajuda de um estilista. O seu sucesso é uma crítica à sociedade consumista que materializa e comercializa qualquer objeto e pessoa em função do lucro ${ }^{5}$. A personagem, assim como os restos mortais das pessoas que sucumbiram à epidemia, é um produto de comercialização.

Seus pedaços eram recolhidos pelos caminhões de limpeza e encaminhados aos ferros-velhos, onde seriam vendidos como sucata.

\footnotetext{
5 A comercialização da imagem da robô e dos estilhaços dos "doentes" pode ser comparada à comercialização da imagem de diversos personagens históricos, como, por exemplo, a de Chê Guevara(1928-1967), pois o revolucionário foi perseguido e morto pelo governo militar colombiano e atualmente, sua imagem é amplamente comercializada em artigos de decoração e de vestuário.
} 
Esperava-se também que a epidemia fosse completamente esquecida pela faixa normal da população e futuramente braços e pernas pudessem ser utilizados como objetos decorativos. Esperava-se ainda industrializar estilhaços dos olhos para transformá-los em contas coloridas que seriam usadas na confecção de colares para serem vendidos a turistas ávidos de exotismo.(...) Os costureiros lançaram a linha-robô, com roupas inteiramente de aço e maquiagem metálica, os oculistas criaram novas lentes de contato acrílicas, especialmente para dar aos olhos o efeito de vidro. (...) Tornou-se extremamente chique frequentar oficinas mecânicas. (ABREU, 1992:32-33)

A ascensão e a queda, as quais o título do conto faz referência, não correspondem ao sucesso de Robhéa como modelo e ao seu isolamento. A ascensão de Robhéa acontece quando a modelo abandona sua carreira, o luxo e a ostentação para viver isoladamente, longe do sistema imposto pelo Poder, longe do consumismo que desumaniza o ser humano tornando-o um mero produto exposto nas vitrines de lojas. Chevalier e Gheerbrant (1991) ao falarem sobre a simbologia da ascensão, conceituamna como uma operação divinatória e profilática, destinada a salvar um doente, encontrando-lhe a alma roubada por um espírito. A ascensão de Robhéa é o isolamento da sociedade e também a salvação de sua alma que foi corrompida quando o estilista tornou-a um ícone da moda e, a queda da modelo não seria o fim de sua carreira, mas o período em que aceita comercializar sua imagem e age de acordo com os moldes impostos pelo sistema capitalista. Desse modo, em "Admirável chip novo" também observamos a simbologia da ascensão, como uma maneira de romper e de salvar o indivíduo da programação do sistema, porém, na canção essa ascensão não é concretizada, pois a robô não consegue "salvar-se" de uma nova reprogramação ${ }^{6}$

A correspondência entre o título do conto de Caio F. e o desfecho da personagem pode ser vista como uma inversão dos conceitos de "ascensão" e "queda", pois durante uma primeira leitura podemos considerar que a ascensão corresponderia ao sucesso da manequim enquanto a sua queda corresponderia ao seu isolamento e suicídio, mas o narrador inverte este conceito, fazendo com que a ascensão ocorra após sua queda.

Durand (2002) comenta sobre o processo de inversão em que pelo negativo se reconstitui o positivo, por uma negação ou por um ato negativo se destrói o efeito de uma primeira negatividade. A inversão entre um ato negativo e um ato positivo que

\footnotetext{
${ }^{6}$ No fim do clip oficial dessa canção há um tombamento dos robôs, o que podemos referenciar como uma queda das individualidades e dos desejos dessas pessoas diante de um novo modelo imposto através do sistema.

Revista Leitura v.2 no 54 - Júlio/Dez 2014 - Número temático: Leituras interartes. Onde estão meus olhos de robô? $O$ olhar sobre consumismo em Pitty e Caio Fernando Abreu. Simone D. Guardalupe, Luciana Z. Padovani e Ana L. F. Cosme. p.-179 - 192. 
Durand conceitua pode ser estendida à atitude de Robhéa que, após deixar-se moldar pelo sistema, abandona sua carreira de modelo. Nesse ato a robô está ascendendo, pois poderá ser quem realmente deseja, não agindo mais conforme os interesses dos agentes do sistema, como o estilista, os veículos de comunicação ou o Poder.

Percebe-se, em “Ascensão e queda de Robhéa, manequim \& robô”, a ligação entre a influência econômica e a cultura, no sentido de que a criação artística visa a fins lucrativos, em vez de buscar a transcendência. Com isso, pode-se mencionar que os formadores de opinião "operam" a serviço do sistema capitalista, contribuindo para a uniformização da cultura, em níveis globais, conforme pode ser interpretado na seguinte passagem:

Tornaram-se o símbolo da nova mentalidade, e sua casa passou a ser frequentada por escritores inéditos, atores em ascensão, manequins, costureiros promissores, jornalistas em evidência, marchands, diretores de cinema underground e todos que, de uma forma ou de outra, procuravam contribuir para a evolução da cultura ocidental. O movimento tecnológico que a essa altura já influenciava seriamente a música, a literatura, as artes plásticas, a moda e todas as outras formas de expressão - ultrapassou as limitadas fronteiras do país para atingir o mundo inteiro (ABREU, 1992:34).

Aliada à questão cultural, nota-se a problematização sobre o papel das mídias na interpelação ideológica dos sujeitos ${ }^{7}$, visto que a personagem do jornalista no conto atinge a fama ao tornar pública a sua investigação sobre a "peste tecnológica", aparentemente já superada, fato que fez eclodir a tendência robótica em diversos âmbitos, inclusive o artístico. A partir dessa mudança, inscreve-se a "nova mentalidade", a qual, repetidamente noticiada e enfatizada, torna-se senso comum, incentivando o comportamento generalizante e inibindo posicionamentos contrários à ideologia já considerada dominante. Essa perspectiva pode ser encontrada também na música "Admirável chip novo", cujos verbos conjugados no modo Imperativo, vistos nos versos "Pense, fale, compre, beba/Leia, vote, não se esqueça/ Use, seja, ouça, diga/ Tenha, more, gaste e viva" (SOUZA, 2003: v. 12-15), propiciam a alusão aos apelos midiáticos de motivação ao consumo de diferentes bens, sejam eles materiais ou não.

Os apelos midiáticos permeiam a própria constituição do ser humano, fazendo com que o estímulo ao consumo torne-se necessidade vital, ocasionando a inversão de

${ }^{7}$ O teórico Louis Althusser, na obra Aparelhos ideológicos de estado (1985) propõe a associação entre mídia e Estado, na qual as ações do meio publicitário servem à ideologia da respectiva nação de inserção. 
valores, nos quais elementos como o pensamento, o sentimento e a subjetividade passariam a ser adquiridos nos produtos destinados ao consumo. Dessa forma, aspectos intelectuais seriam "descartados", transformando os sujeitos em seres alienados, de acordo com interpretação suscitada no trecho a seguir:

Seus pedaços eram recolhidos pelos caminhões de limpeza e encaminhados aos ferros-velhos onde seriam vendidos como sucata. Esperava-se também que em breve a epidemia fosse completamente esquecida pela faixa normal da população e futuramente braços e pernas pudessem ser utilizados como objetos decorativos (ABREU, 1992:32).

No conto, a alienação pode estar associada ao esquecimento, em virtude da contenção simbólica da ideologia que contraria o poder, representada na queda dos "doentes" de que trata o enredo. Situação semelhante acontece na letra da música de Pitty, ao ser mencionada a expressão "não se esqueça" (verso 13), que pode ser comparada ao cerceamento dos indivíduos perante os interesses do sistema, o qual os induz à busca incessante de aquisição material e, por consequência, contribui para o apagamento da sua essência. Nesse aspecto, tem-se nos dois textos o apagamento da subjetividade em detrimento do apelo mecânico de agir sem refletir sobre sua condição.

No mesmo sentido, nas duas obras percebe-se a presença de elementos que compõem a "peste tecnológica" da qual o conto de Caio F. fala. Tanto no enredo do conto como na letra da música da cantora Pitty, nota-se a tendência dos indivíduos de seguir determinado padrão, ou seja, de cumprir as ordens dadas pelo Poder. No conto, os indivíduos que não aderem, ou se negam, em um primeiro momento, a fazê-lo, são descritos como máquinas descartáveis:

Os doentes - assim haviam sido chamados pelo Poder - não suportavam o processo por mais sete dias. Findo esse prazo, tombavam nas praças e ruas, os olhos de vidro explodindo em pedaços coloridos, as engrenagens enferrujadas não correspondendo às ordens dos cérebros enfraquecidos. Alguns tomavam doses enormes de estimulantes para que o cérebro, funcionando quase em sua totalidade, enviasse ordens cada vez mais violentas aos membros entorpecidos (ABREU, 1992:31).

Da mesma forma, na música, percebe-se características que fazem do eulírico

Revista Leitura v.2 no 54 - Júlio/Dez 2014 - Número temático: Leituras interartes. Onde estão meus olhos de robô? $O$ olhar sobre consumismo em Pitty e Caio Fernando Abreu. Simone D. Guardalupe, Luciana Z. Padovani e Ana L. F. Cosme. p.-179 - 192. 
um ser, como Robhéa, robotizado: "Pane no sistema, alguém me desconfigurou/ aonde estão meus olhos de robô" (SOUZA, 2003: v. 1 e 2); "Parafuso e fluido em lugar de articulação (SOUZA, 2003: v. 5); "Nada é orgânico, é tudo programado" (SOUZA, 2003: v. 7). A partir desses versos, vê-se que, assim como no conto, ocorre a desconstrução humana para a ascensão da máquina - o que determina uma peste tecnológica: o robô em detrimento do humano.

Embora nos dois textos ocorra a desumanização em troca do surgimento dos seres robotizados e a tomada de consciência, mesmo que temporária, da condição de vida da personagem ou do eu lírico, Robhéa e o eu lírico da canção agem de forma distinta em relação à pressão social que sofrem. No conto, a robô acaba corrompida pelo Poder, inclusive tornando-se um ícone da moda, mas, ao final, afasta-se da situação de dominação que a envolve, quando se muda para a ilha deserta. Enquanto na música, o sistema promove um ciclo de reinserções do indivíduo, mesmo que ele tenha tomado consciência de sua situação.

Sendo assim, Robhéa, ao isolar-se da sociedade, consegue libertar-se de uma condição imposta, já o eulírico não consegue essa ascensão, pois ocorre uma nova reprogramação do sistema. Enquanto Robhéa consegue fugir desse circulo vicioso do capitalismo por atitude própria, o eu lírico da música depende de uma "pane no sistema" para conscientizar-se de sua realidade, mesmo assim ele não consegue libertar-se desse sistema e volta à sua condição de robótica.

\section{Considerações Finais}

A simbologia do olhar perpassa os dois textos analisados, revelando todos os fatores desencadeados a partir da adoção de uma forma de organização pautada pelo consumismo e pela obediência às regras impostas seja pelo Poder ou pelo sistema. É ao olhar o ambiente à sua volta que Robhéa consegue transgredir os modelos e ideais veiculados pelo Poder na sociedade do conto de Caio Fernando Abreu. Já na letra da música "Admirável chip novo", os olhos de robô perdidos, programados pelo poder para obedecer, para comprar, consumir e pensar de acordo com a sua configuração bem como a referência a uma nova reinstalação do sistema levam à conclusão de que o eulírico subverte a ordem em alguns momentos, mas não chega a transgredi-la, visto que esta volta a ser reprogramada.

Revista Leitura v.2 no 54 - Júlio/Dez 2014 - Número temático: Leituras interartes.
Onde estão meus olhos de robô? O olhar sobre consumismo em Pitty e Caio Fernando
Abreu. Simone D. Guardalupe, Luciana Z. Padovani e
Ana L. F. Cosme. p.-179 - 192. 
Além disso, nota-se que as críticas, principalmente em relação ao consumismo, à violência e à fragmentação do homem ainda são pertinentes, embora o escritor tenha falecido há quase vinte anos e a música analisada já tenha completado mais de dez anos. Tal consideração remonta ao sistema econômico capitalista, o qual teve sua prática mais evidente a partir da década de 1970, período retratado por Caio F., sendo intensificada na atualidade, através da globalização.

Nesse sentido, pode-se pensar que os dois materiais convergem para as inquietações do homem contemporâneo, que tem acesso à informação, à tecnologia e ao deslocamento de forma mais intensa e, ao mesmo tempo, está imerso no processo de homogeneização da cultura, muitas vezes, sofrendo a violência do cerceamento, em consequência da não adequação ao estilo de vida ou aos discursos dominantes, ou de Poder, como representa o autor sul-rio-grandense. Sendo assim, os indivíduos não integrados nesse sistema, passam a refletir sobre os rumos sociais e intelectuais da humanidade, também retratados nas duas obras aqui utilizadas, mesmo que, constantemente, sejam interpelados por essa ideologia e não consigam romper com a estrutura econômico-social mais ampla, como ficou evidente na interpretação da canção de Pitty.

\section{Referências Bibliográficas}

ABREU, Caio Fernando. Ficção nos tempos do cólera.[S.L.:Sn.]. Entrevista concedida à Sônia Coutinho.

"Ascensão e Queda de Robhéa, Manequim \& Robô". In: O ovo apunhalado. São Paulo: Siciliana, 1992.

ALTHUSSER, Louis. Aparelhos ideológicos de Estado.Trad. de Valter José Evangelista e Maria Laura Viveiros de Castro. Rio de Janeiro: Graal, 1985.

CHAVES, Flávio Loureiro. O Ovo e a urgência de dizer. Porto Alegre: Correio do Povo, 10 mai. 1976. Caderno de sábado.

CHEVALIER, Jean \& GHEERBRANT. Alain. Dicionário de símbolos: mitos, sonhos, costumes, gestos, figuras, cores, números. Tradução de Vera de Sá Costa e Silva. Rio de Janeiro: J. Olympio, 1991.

CIRLOT. Jean-Eduardo. Dicionário de símbolos. Tradução de Rubens Eduardo Ferreira Frias. São Paulo: Centauro, 2005.

DURAND, Gilbert. As estruturas antropológicas do imaginário. 3. Ed. São Paulo: Martins Fontes, 2002. A fé do sapateiro. Brasília: UNB, 1995.

Paulo, 1988 .

Revista Leitura v.2 no 54 - Júlio/Dez 2014 - Número temático: Leituras interartes. Onde estão meus olhos de robô? O olhar sobre consumismo em Pitty e Caio Fernando Abreu. Simone D. Guardalupe, Luciana Z. Padovani e Ana L. F. Cosme. p.-179 - 192. 
HARVEY. David. Condição pós-moderna: uma pesquisa sobre as origens da mudança cultural. Tradução de Maria Stela Gonçalves. São Paulo: Loyola, 1994

JUNG, Carl G. O Homem e seus símbolos. Tradução de Maria Lúcia Pinho. Rio de Janeiro: Nova Fronteira, 1964.

INFOESCOLA. Economia Brasileira entre 2001 e 2011. Disponível em <http://www.infoescola.com /historia/economia-brasileira-entre-2001-e-2011/>. Acesso em 19 nov. 2014.

INTERAGINDO COM A LINGUÍSTICA. Análise da música: "Admirável Chip Novo" (Pitty) e a intertextualidade com o livro "Admirável Mundo Novo" (Aldous Huxley). Disponível em <http://interagilinguistica.blogspot.com.br/2010/11/analise-da-musicaadmiravel-chip-novo_25.html>. Acesso em 18 nov. 2014.

PICCHIO, Luciana Stegagno. 1964 - 1996: Dos anos de Golpe ao Fim do Século. In: História da literatura brasileira. Rio de Janeiro: Nova Aguilar,1992, p.646 - 647.

SOUZA, Pitty. "Admirável Chip Novo". Admirável Chip Novo. Intérprete Pitty. Rio de Janeiro: DECKdisc, 2003. Disponível em < http://letras.mus.br/pitty/admiravel-chipnovo/>. Acesso em 02 jun 2013.

ROLlingSTONE. Disco de estreia da Pitty, Admirável Chip Novo completa 10 anos e ganha lançamento em vinil. Disponível em < http://rollingstone.uol.com.br/noticia/disco-de-estreia-da-pitty-iadmiravel-chip-novoicompleta-10-anos-e-ganha-lancamento-em-vinil/>. Acesso em 18 nov. 2014.

SILVA, Francisco Carlos Teixeira da. Brasil, em direção ao século XXI. In: LINHARES, Maria Yeda (org.). História geral do Brasil. 9. ed. Rio de Janeiro:

ZILBERMAN, Regina. Brasil: Cultura e literatura nos anos 80. Organon. Porto Alegre: Instituto de Letras da Universidade Federal do R.G.S, nº 17, p. 93 - 103,1991.

Revista Leitura v.2 no 54 - Júlio/Dez 2014 - Número temático: Leituras interartes. Onde estão meus olhos de robô? O olhar sobre consumismo em Pitty e Caio Fernando Abreu. Simone D. Guardalupe, Luciana Z. Padovani e Ana L. F. Cosme. p.-179 - 192. 